\title{
Efeito da monensina e do óleo de soja sobre os protozoários ciliados do rúmen e correlação dos protozoários com parâmetros da fermentação ruminal e digestivos ${ }^{1}$
}

\author{
Isabel Martinele ${ }^{1}$, Eduardo da Costa Eifert ${ }^{2}$, Rogério de Paula Lana ${ }^{3}$, Pedro Braga Arcuri ${ }^{4}$, \\ Marta D‘Agosto 5
}

\author{
1 Projeto parcialmente financiado pelo CNPq. \\ 2 EMBRAPA Arroz e Feijão, Santo Antônio de Goiás, GO. \\ ${ }^{3}$ Departamento de Zootecnia, UFV. Viçosa, MG, Brasil. \\ ${ }^{4}$ EMBRAPA Gado de Leite, Juiz de Fora, MG, Brasil. \\ ${ }^{5}$ Departamento de Zoologia, Instituto de Ciências Biológicas - UFJF, Juiz de Fora, MG, Brasil.
}

RESUMO - Quatro vacas lactantes canuladas no rúmen, com 155 dias em lactação, foram dispostas em um quadrado latino $4 \times 4$ e alimentadas, duas vezes ao dia, com silagem de milho e concentrado (relação 55:45, base matéria seca), para se avaliarem os efeitos da monensina e do óleo de soja na dieta de vacas lactantes sobre a contagem de protozoários ciliados, além de estabelecer correlações entre os protozoários com alguns parâmetros da digestão e da fermentação ruminal. Os tratamentos consistiram da inclusão de 33 ppm de monensina sódica ou de 4\% de óleo de soja na dieta, assim representados: dieta controle, sem óleo ou monensina - CT; dieta com monensina - MN; dieta com óleo - OL; combinação de 33 ppm de monensina e 4\% de óleo de soja - OM. Verificou-se a ocorrência de 11 gêneros de ciliados, sendo Entodinium o predominante em todos os tratamentos. Não foi observada interação significativa óleo de soja $\times$ monensina sobre a contagem de protozoários e gêneros. Os gêneros Entodinium, Dasytricha, Eremoplastron e Isotricha foram reduzidos nas dietas com óleo, enquanto a monensina diminuiu a contagem de Dasytricha, Eremoplastron e Epidinium. O número total de protozoários e de ciliados celulolíticos foi reduzido pelos efeitos de óleo de soja e monensina, indicando efeito aditivo defaunatório quando combinados o óleo e a monensina. Os ciliados celulolíticos foram reduzidos pelo consumo de ácido linoléico e positivamente relacionados à digestibilidade ruminal da FDN e amônia ruminal. O número total de protozoários foi correlacionado à proporção de propionato no líquido ruminal, indicando que monensina e óleo de soja, pelo seu efeito defaunatório, podem reduzir a perda de metano no rúmen.

Palavras-chave: bovinos, Ciliophora, lipídios, ionóforo, metano

\section{Effect of monensin and soybean oil on rumen ciliate protozoa and correlation between protozoa with ruminal fermentation and digestive parameters}

\begin{abstract}
Four lactating dairy cows with ruminal cannula and 155 DIM were allotted to a $4 \times 4$ Latin square and fed twice daily corn silage and concentrate $(55: 45, \% \mathrm{DM})$ to evaluate the effect of monensin and soybean oil in the diet of lactating cows on the counting of ciliate protozoa beyond establishing correlations between number of protozoa with some parameters of digestion and ruminal fermentation. The treatments consisted of the inclusion of 33 ppm of sodium monensin or soybean oil at 4\% DM, as following: control diet, without oil or monensin - CT; diet with monensin - MN; diet with soybean oil - OL; diet with the combination of $33 \mathrm{ppm}$ of monensin and $4 \%$ of soybean oil - OM. Occurrence of 11 ciliate genera was observed, being Entodinium the predominant in all treatments. No significant soybean oil $\times$ monensin interaction was observed on protozoa number and genera. The genera Entodinium, Dasytricha, Eremoplastron and Isotricha reduced in the diets with oil, while monensin reduced the counting of Dasytricha, Eremoplastron and Epidinium. The total number of ciliate protozoa and cellulolytics protozoa was reduced by soybean oil and monensin effects, showing a defaunatory additive effect when combined the oil and the monensin. The ciliate cellulolytics was reduced by linoleic acid intake and was related positively with NDF ruminal digestibility and ruminal ammonia. The total number of protozoa was correlated with the molar proportion of propionate in the ruminal liquid, suggesting that monensin and soybean oil, due their defaunatory effect, can reduce the loss of methane in the rumen.
\end{abstract}

Key Words: cattle, Ciliophora, fats, ionophore, methane 


\section{Introdução}

Elevar a utilização da energia no rúmen, maximizar a utilização do nitrogênio pelas bactérias ruminais e reduzir as perdas por metano e amônia são alguns objetivos dos nutricionistas para aumentar com eficiência o desempenho animal. Uma das alternativas para atingir esses objetivos envolve a manipulação da fermentação ruminal, onde o complexo ecossistema hidrolisa e fermenta a fibra e demais nutrientes até produtos úteis e disponíveis ao hospedeiro que habita (Eugène et al., 2004).

Enquanto maior atenção tem sido dada às bactérias ruminais, protozoários podem utilizar a maioria dos carboidratos solúveis, amido e carboidratos da parede celular para seu crescimento, além de estarem associados à maior reciclagem de nitrogênio microbiano no rúmen e à redução no suprimento de aminoácidos ao intestino (Ivan et al., 2001). Protozoários apresentam simbiose com arquéias metanogênicas, onde o hidrogênio produzido pelos ciliados é utilizado por estes microrganismos na formação de metano. Os protozoários podem ser responsáveis por até 37\% da metanogênese (Williams \& Coleman, 1997) e, assim, a redução no número de ciliados torna-se interessante, em razão da menor perda de energia no rúmen e das conseqüências ambientais do metano no efeito estufa.

Muitas pesquisas têm sido feitas para identificar o papel específico dos protozoários no metabolismo ruminal e a inter-relação das espécies no rúmen. Entretanto, o cultivo in vitro dos ciliados é difícil e a sobrevivência de alguns ciliados depende da presença de bactérias e arquéias no meio (Williams \& Coleman, 1997). Por outro lado, a manutenção de animais livres de protozoários por longos períodos é também difícil, porém, os estudos in vivo trazem o benefício de permitir a análise de parâmetros digestivos e de desempenho de animais faunados e defaunados (Eugène et al., 2004).

Eugène et al. (2004), utilizando os dados reportados na literatura de animais faunados e defaunados em um estudo em meta-análise, observaram que a defaunação decresceu a digestibilidade da material orgânica (1,7 unidades) e da FDN (5,7 unidades). A defaunação também propiciou maior passagem de nitrogênio microbiano ao duodeno (21\%) e aumentou a eficiência de síntese microbiana (11,8 g N/kg MODR), com redução da concentração de amônia ruminal $\left(-5,03 \mathrm{mg} \mathrm{N}-\mathrm{NH}_{3} / \mathrm{dL}\right)$. A concentração de propionato foi aumentada, enquanto a proporção de butirato foi reduzida.

A monensina é um ionóforo que tem sido bastante utilizado na dieta de ruminantes e os efeitos decorrentes do seu uso no desempenho animal são bem relatados na literatura. Os efeitos no desempenho são conseqüência da manipulação da fermentação ruminal, a partir do controle da atividade das bactérias gram-positivas, sensíveis ao ionóforo. Protozoários também são sensíveis à monensina, porém seu efeito é transitório, pois os ciliados retornam seu crescimento 3-4 semanas após o início do fornecimento do ionóforo (Guan et al., 2006). Fontes de lipídios insaturados, como o óleo de soja, também apresentam propriedades dafaunadoras (Moss et al., 2000) e interferem na atividade das bactérias gram-positivas, de maneira similar aos ionóforos.

À medida que os protozoários têm seu crescimento estimulado ou inibido por fatores dietéticos (Towne et al., 1990; Franzolin \& Franzolin, 2000; Guan et al., 2006), torna-se importante avaliar os efeitos do fornecimento simultâneo de óleo de soja e de monensina sobre a população de ciliados e os gêneros que a compõe, sendo este um dos objetivos deste trabalho. Também fazem parte dos objetivos do trabalho estudar as possíveis correlações entre a população de ciliados com alguns parâmetros de consumo, fermentação ruminal e digestão de nutrientes no rúmen, no intuito de gerar informações que possam resultar em estratégias alimentares que aumentem a eficiência na alimentação de ruminantes.

\section{Material e Métodos}

Este experimento foi desenvolvido no Centro Nacional de Pesquisa de Gado de Leite da Empresa Brasileira de Pesquisa Agropecuária (CNPGL/EMBRAPA), situado no município de Coronel Pacheco, MG.

Foram utilizadas quatro vacas multíparas cruzadas 7/8 Holandês Zebu dotadas de cânulas ruminais, com 155 dias em lactação e peso corporal médio de 591 kg. Os animais foram confinados em free-stall, com dispositivo eletrônico para alimentação individual (callan-gates) e cochos com água à vontade. As dietas experimentais (Tabela 1) foram formuladas à base de silagem de milho e concentrado, na relação 55:45, com base na matéria seca, para atender à necessidade de nutrientes de vacas com produção de leite de $25 \mathrm{~kg} /$ dia, com 3,0\% de gordura e 3,5\% de proteína, segundo o NRC (2001).

Os tratamentos consistiram de uma dieta controle (CT), dieta com monensina a 33 ppm (MN), dieta com óleo de soja a $4 \%$ na MS (OL) e dieta com óleo de soja e monensina $(\mathrm{OM})$. $\mathrm{O}$ ensaio experimental, em quadrado latino $4 \times 4$, constou de quatro períodos experimentais de 21 dias, sendo 14 dias de adaptação à dieta e sete dias de coletas de amostras de conteúdo ruminal. 
Tabela 1 - Composição em ingredientes e nutricional das dietas experimentais

\begin{tabular}{lcc}
\hline Item & \multicolumn{2}{c}{ Dieta } \\
\cline { 2 - 3 } & Sem óleo & Com óleo \\
\hline Ingrediente $^{1}$ & & \\
Silagem de milho & 55,11 & 54,52 \\
Concentrado & 44,89 & 41,55 \\
Óleo de soja & - & 3,93 \\
\hline Composição química, \% & & \\
\hline Proteína bruta & 16,48 & 16,12 \\
FDN & 37,35 & 36,74 \\
Extrato etéreo & 2,44 & 6,19 \\
Ácidos graxos, g/100 g & & \\
$C_{12: 0}$ & 2,4 & 2,4 \\
$C_{14: 0}$ & 0,3 & 0,3 \\
$C_{16: 0}$ & 15,5 & 0,3 \\
$C_{16: 1}$ & 0,4 & 2,9 \\
$C_{18: 0}$ & 2,6 & 20,2 \\
$C_{18: 1}$ & 20,5 & 50,3 \\
$C_{18: 2}$ & 46,6 & 3,2 \\
$C_{18: 3}$ & 2,1 & 9,2 \\
\hline
\end{tabular}

${ }^{1}$ Nos tratamentos com monensina sódica: 33 ppm no concentrado.

Os animais foram alimentados duas vezes ao dia, às $6 \mathrm{~h} 30$ e 15h30, logo após a ordenha, que foi realizada nestes mesmos horários. As amostras de conteúdo ruminal foram obtidas de coletas manuais, em cinco locais distintos da porção ventral do rúmen, entre três e quatro horas após a alimentação matinal dos animais. O material coletado foi acondicionado em garrafas térmicas e enviado ao laboratório para determinação das espécies e contagem de protozoários.

No laboratório, as amostras foram fixadas em formalina 18,5\% (v/v) (Dehority, 1984) e analisadas no Laboratório de Protozoologia do Programa de Pós-Graduação em Ciências Biológicas - Comportamento e Biologia Animal, Universidade Federal de Juiz de Fora, MG. Os gêneros de ciliados foram identificados e avaliados quantitativamente em câmara de contagem Sedgewick-Rafter, segundo Dehority (1984), com modificações propostas por D’Agosto \& Carneiro (1999), sendo os resultados expressos como o número de ciliados por mililitro de conteúdo ruminal. A identificação dos ciliados foi realizada segundo Ogimoto \& Imai (1981).

Os dados da contagem de protozoários ciliados foram submetidos à análise de variância, utilizando o comando Proc GLM do SAS (1997). Os dados foram transformados para $\log _{10}$, acrescidos de uma unidade para atender aos requerimentos da análise do SAS para observações diferentes de zero. Os efeitos de óleo, monensina e da interação vaca × período foram incluídos no modelo. Os dados de consumo, digestibilidade e parâmetros de fermentação (Tabela 2),
Tabela 2 - Médias das variáveis utilizadas nas correlações com protozoários $^{1}$

\begin{tabular}{|c|c|c|c|c|}
\hline \multirow[t]{2}{*}{ Item } & \multicolumn{4}{|c|}{ Tratamento } \\
\hline & $\mathrm{CT}$ & $\mathrm{MN}$ & OL & $\mathrm{OM}$ \\
\hline & \multicolumn{4}{|c|}{ Consumo diário, kg/dia } \\
\hline Matéria seca & 17,8 & 17,2 & 15,3 & 14,7 \\
\hline Ácidos graxos & 0,263 & 0,253 & 0,844 & 0,798 \\
\hline \multirow[t]{2}{*}{ Ácido linoléico } & 0,123 & 0,118 & 0,425 & 0,401 \\
\hline & \multicolumn{4}{|c|}{ Parâmetro da fermentação ruminal } \\
\hline $\mathrm{pH}$ & 6,34 & 6,35 & 6,38 & 6,35 \\
\hline $\mathrm{N}-\mathrm{NH}_{3}, \mathrm{mg} / \mathrm{dL}$ & 12,3 & 11,66 & 9,41 & 10,79 \\
\hline $\mathrm{AGV}, \mathrm{mM}$ & 106,6 & 97,8 & 100,5 & 92,8 \\
\hline
\end{tabular}

Proporção molar de ácidos graxos, mMol \%

\begin{tabular}{|c|c|c|c|c|}
\hline Acetato (A) & 71,7 & 67,9 & 69,4 & 67,7 \\
\hline Propionato (P) & 22,4 & 25,5 & 25,3 & 26,8 \\
\hline Butirato & 5,90 & 6,60 & 5,32 & 5,46 \\
\hline Rel. A:P & 3,21 & 2,70 & 2,79 & 2,56 \\
\hline & \multicolumn{4}{|c|}{ Síntese microbiana } \\
\hline NMic, g/dia & 231,9 & 227,1 & 203,1 & 178,6 \\
\hline \multirow[t]{2}{*}{ EfSM, g N/kg MODR } & 25,9 & 26,0 & 24,2 & 25,4 \\
\hline & \multicolumn{4}{|c|}{ Digestibilidade ruminal, \% } \\
\hline MO & 50,65 & 52,97 & 54,42 & 51,78 \\
\hline PB & 30,82 & 31,79 & 31,86 & 32,01 \\
\hline FDN & 43,68 & 45,71 & 45,08 & 39,75 \\
\hline
\end{tabular}

${ }^{1}$ Dados reportados por Eifert et al. (2005).

reportados por Eifert et al. (2005), foram utilizados para estabelecer a correlação entre os dados de protozoários, utilizando-se o comando Proc Corr do SAS (1997), considerando-se nível de significância de $10 \%$.

\section{Resultados e Discussão}

Foram identificados e quantificados 11 gêneros: Dasytricha, Diplodinium, Entodinium, Eodinium, Epidinium, Eremoplastron, Eudiplodinium, Isotricha, Metadinium, Ostracodinium e Polyplastron (Tabela 3).

A composição dos gêneros e a contagem numérica das populações de protozoários variaram conforme o hospedeiro (vaca) e os tratamentos (dieta). Somente na dieta controle todos os gêneros de protozoários foram observados, ao passo que apenas os gêneros Entodinium e Ostracodinium foram verificados em todas as dietas. Em relação ao hospedeiro, apenas os gêneros Entodinium, Ostracodinium e Eremoplastron foram observados em todos os animais, independentemente da dieta.

Os gêneros Diplodinium e Polyplastron foram verificados somente em um hospedeiro, quando este foi submetido à dieta controle; portanto, estes dados não foram incluídos na análise estatística. Embora não tenha 
Tabela 3 - Contagem e identificação dos gêneros de protozoários ciliados no conteúdo ruminal (número x104/mL de conteúdo ruminal)

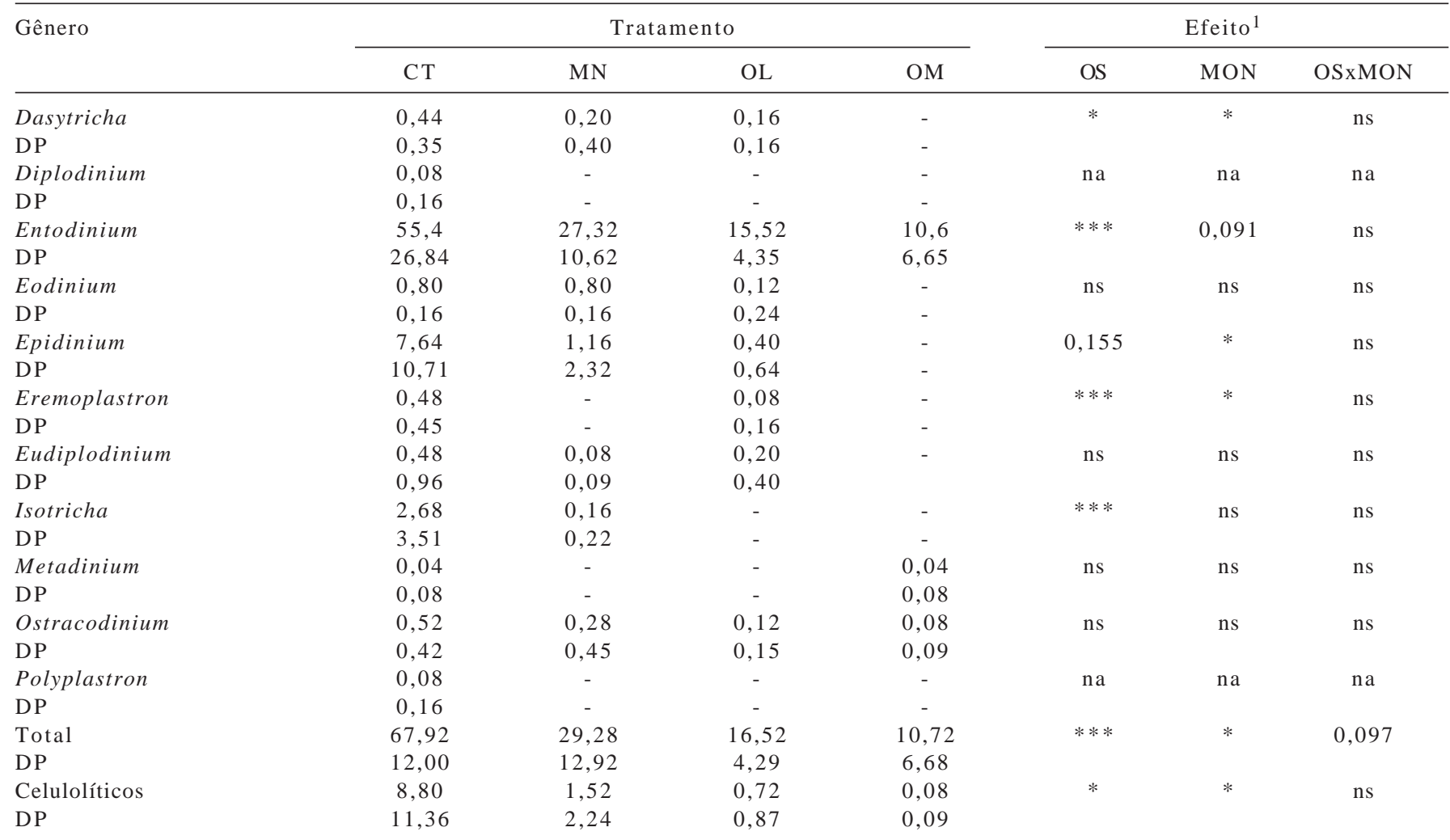

Celulolíticos = Diplodinium, Eudiplodinium, Ostracodinium, Polyplastron e Epidinium

* $P<0,05$; *** $P<0,001$; ns - não-significativo $(P>0,05)$; na - não-aplicável.

${ }^{1}$ Efeitos de óleo de soja (OS), da monensina (MON) e interação (OS × MON).

sido verificado efeito de período sobre a contagem de protozoários, a observação de que nem todos os animais tenham apresentado todos os gêneros de protozoários permite questionar se o tempo destinado à adaptação dos animais às dietas na seqüência do quadrado latino foi suficiente para restabelecer a comunidade de protozoários, principalmente nas seqüências das dietas OL e OM.

A variação da contagem de protozoários entre os hospedeiros foi refletida nos altos desvios-padrão observados neste trabalho, que também foram verificados por outros autores (Towne et al., 1990; Ivan et al., 2001; Dayani et al., 2007). Franzolin \& Dehority (1996) mostraram que, de cinco animais alimentados com a mesma dieta, rica em concentrado, dois apresentaram defaunação; assim, os animais poderiam ser divididos em dois grupos distintos quanto à comunidade de protozoários presentes no rúmen. Esses autores relataram que o $\mathrm{pH}$ ruminal do grupo defaunado foi menor, comprovando que características relacionadas ao nível e hábito de consumo e a aspectos fisiológicos quanto à ruminação, salivação e tamponamento ruminal têm marcada influência sobre a manutenção de espécies de protozoários no rúmen.

A variação na composição das populações de ciliados dos animais possivelmente indicou a influência do fator individual do hospedeiro e o reconhecimento do perfil de comunidade dos protozoários como sendo do tipos B, caracterizado pela presença de organismos dos gêneros Epidinium associados ou não a Eudiplodinium, e do tipo $O$, que se caracteriza pela ausência de grandes entodiniomorfos. Dois animais apresentaram perfil de comunidade do tipo B, prevalente na dieta controle, alterando-se para o tipo $\mathrm{O}$, de acordo com a adição de óleo de soja ou monensina à dieta. Os demais animais apresentaram perfil do tipo O em todos os tratamentos. Sugere-se que a diferença entre os perfis de comunidade observada ocorreu em função de relações de antagonismo e competição estabelecidas entre alguns gêneros de ciliados, além de fatores metabólicos individuais envolvidos, tanto da espécie, como do hospedeiro (D’Agosto \& Santa-Rosa, 1998; Siqueira \& D'Agosto, 2003).

$\mathrm{Na}$ contagem dos microrganismos, os do gênero Entodinium foram predominantes, representando 81,5; 93,3; 94 e 98,8\% do número total de protozoários nas dietas controle, monensina, óleo e óleo+monensina, respectivamente. A predominância do gênero Entodinium está de acordo com as observações de outros autores que investigaram as populações de protozoários de bovinos em diferentes situações alimentares, por exemplo, em dietas ricas em 
cana-de-açúcar (Franzolin \& Franzolin, 2000), em dietas ricas em concentrado, com ou sem a adição de gordura (Towne et al., 1990), ou com o uso de ionóforos em dietas ricas em volumoso ou concentrado (Guan et al., 2006).

Nesta pesquisa (Tabela 3), observou-se que o gênero Entodinium apresentou populações significativamente menores nas dietas que continham óleo de soja, associado ou não à monensina (tratamentos $\mathrm{OL}$ e $\mathrm{OM}$ ), o que indica um efeito tóxico dos lipídios do óleo de soja sobre esse gênero. Por outro lado, a monensina promoveu redução numérica em Entodinium, mas seu efeito somente foi verificado a $\mathrm{P}=$ 0,09. Esta observação é similar à de Valinote et al. (2005), que encontraram médias significativamente menores dos gêneros Entodinium, Eudiplodinium e do número total de protozoários em tratamentos que continham caroço de algodão como fonte de lipídio, enquanto o tratamento com monensina não provocou alteração sobre as populações de protozoários das dietas com caroço.

Além da redução nos organismos do gênero Entodinium, o óleo de soja também reduziu significativamente a contagem dos gêneros Dasytricha, Eremoplastron e Isotricha. Nas dietas OM, não foi verificada a ocorrência dos gêneros Diplodinium, Eodinium, Epidinium e Eudiplodinium, o que indica um efeito defaunatório.

Como conseqüência da redução na contagem dos gêneros, o número total de protozoários foi reduzido tanto por efeito de óleo de soja, como por efeito da monensina. A redução na contagem de protozoários em relação à dieta controle foi de 43,1; 24,32 e 15,8\%, respectivamente, para as dietas MN, OL e OM. Assim, os efeitos isolados de óleo de soja e da monensina indicam que a utilização conjunta de ambos os tratamentos apresenta efeito aditivo ao reduzir a população de ciliados no rúmen.

O efeito negativo de lipídios sobre os protozoários parece depender da composição de gordura e da forma como a gordura é liberada no rúmen. Valinote et al. (2006) mostraram que sais de cálcio do ácido linoléico não alteraram as populações de ciliados em relação à dieta controle, porém, a contagem foi maior que na dieta com ácido linoléico oriundo do caroço de algodão. Experimentos in vitro e in vivo mostraram que protozoários são sensíveis aos ácidos graxos insaturados C18:3, C18:2 e C18:1, nesta ordem de influência (Machmüller et al., 1998; Hristov et al., 2004), e aos ácidos saturados C8:0 a C14:0 (Dohme et al., 1999), com maior efeito defaunatório para os lipídios saturados (Machmüller et al., 1998).

A monensina tem apresentado resultados contraditórios sobre a comunidade de ciliados no rúmen em relação à sua eficácia ou aos gêneros abrangidos. Estudos de curta duração demonstram redução no número de protozoários, enquanto a comunidade de protozoários retorna o crescimento após três semanas de fornecimento, como observado por Guan et al. (2006), com monensina combinada ou não com lasalocida, comprovando que o efeito dos ionóforos é transitório e os ciliados podem criar resistência aos ionóforos quando utilizados por períodos mais longos.

Rogers et al. (1997) mostraram que o efeito negativo da monensina sobre os protozoários decresceu ao longo do tempo em animais alimentados com dietas com alto concentrado e a intensidade deste efeito foi dependente do tipo de protozoário. Para os autores, Entodinium foi inibido enquanto o número de Isotricha aumentou como resultado da suplementação de monensina. Já Arakaki et al. (2000) mostraram que a diminuição no número de Entodinium pela monensina foi acompanhada por aumento na contagem de Dasytricha. Neste trabalho, as dietas que continham monensina reduziram $(\mathrm{P}<0,05)$ a contagem de Dasytricha, Eremoplastron e Epidinium, e em relação à dieta CT, embora sem diferença significativa, a dieta MN mostrou menor número de indivíduos dos gêneros Eudiplodinium, Isotricha e Ostracodinium.

As populações de protozoários que apresentam celulases e hemicelulases, denominados celulolíticos e compostos pelos gêneros Diplodinium, Eudiplodinium, Ostracodinium, Polyplastron e Epidinium (Williams \& Coleman, 1997; Ivan et al., 2001; Dayani et al., 2007), também foram reduzidas tanto por efeito de óleo e soja, como de monensina. As médias observadas para os protozoários celulolíticos, de 8,$80 ; 1,52 ; 0,72$ e $0,08 \times 10^{4} / \mathrm{mL}$ para as dietas CT, MN, OL e OM, respectivamente, poderiam sugerir maior efeito de óleo que monensina sobre estes gêneros. Entretanto, a proporção dos celulolíticos em relação ao total de protozoários foi de 12,96; 5,19; 4,35 e 0,75\% para as dietas CT, MN, OL e OM, respectivamente, indicando que não houve redução seletiva nos gêneros celulolíticos devido ao óleo de soja ou monensina na dieta. Por outro lado, o uso simultâneo de óleo de soja e de monensina na dieta sugere efeito aditivo sobre os celulolíticos, com defaunação quase completa na dieta OM. Ivan et al. (2001) observaram reduções similares dos celulolíticos, de 2,7 e 1\% para dietas controle e $6 \%$ de óleo de girassol, e ressaltam que diferença na contagem destes protozoários foi ampliada com o decorrer do período experimental.

Neste trabalho, o número de protozoários celulolíticos foi negativamente relacionado ao consumo de ácidos graxos (CAG) ou de ácido linoléico (CLIN), ambos com $r=-0,47$ (Tabela 4), o que confirma o efeito dos lipídios insaturados sobre protozoários, como relatado por Machmüller et al. (1998) e Hristov et al. (2004). Entretanto, não se verificou correlação com o consumo dos demais lipídios insaturados, 
C18:1 e C18:3 (dados não apresentados), possivelmente em razão da baixa concentração de C18:3 nas dietas e do fato de o C18:1 ser menos tóxico que C18:2 e C18:3, além de sofrer intensa bio-hidrogenação no rúmen (Hristov et al., 2004). O mesmo comportamento de inibição pelo CAG e CLIN foi verificado para o total de protozoários, com $r=-0,56$ para ambos.

O total de protozoários e os celulolíticos não foram correlacionados ao consumo de matéria seca (CMS), o que está de acordo com o estudo em meta-análise de Eugène et al. (2004), com animais faunados e defaunados. Neste caso, poderia ser esperado maior CMS pelo auxílio dos protozoários na digestão da fração fibrosa dos alimentos e na manutenção do $\mathrm{pH}$ ruminal pelo engolfamento de partículas de amido. Embora o CMS tenha sido reduzido nas dietas OL e OM, que apresentaram defaunação, a falta de correlação com a fauna microbiana indica que outros fatores estejam envolvidos. Os fatores que regulam o CMS têm caráter multifatorial, que envolvem, além de aspectos comportamentais, as características das dietas, do ambiente ruminal e do animal. Neste contexto, Eifert et al. (2005) sugeriram que os tratamentos podem ter influenciado o consumo por diferentes mecanismos, que envolvem a atividade microbiana nos processos digestivos no rúmen, a necessidade energética do hospedeiro e a utilização dos nutrientes absorvidos e metabolizados pelo animal. Assim, devido à complexidade dos fatores regulatórios, torna-se difícil isolar a influência dos protozoários sobre o CMS.

A literatura tem apresentado os efeitos da fauna ruminal sobre o metabolismo do nitrogênio no rúmen, que envolvem a síntese microbiana, predação e formação de amônia ruminal (Williams \& Coleman, 1997). Entretanto, não foram observadas correlações dos protozoários com a digestibilidade da proteína e da matéria orgânica no rúmen ou na síntese e eficiência microbiana. Segundo Doreau \& Ferlay (1995), lipídios insaturados têm pouca influência sobre a síntese microbiana, observando-se aumentos na eficiência da síntese microbiana com maior freqüência quando há redução no número de protozoários ou digestibilidade da MO no rúmen. Eifert et al. (2005) relataram que a síntese microbiana foi reduzida por efeito do óleo de soja e da monensina, sem apresentar diferenças para a eficiência de síntese microbiana (em g N/kg MODR), que foi justificada por efeitos inibitórios dos tratamentos sobre o crescimento bacteriano, principalmente na dieta OM.

Eifert et al. (2005) observaram interação óleo de soja × monensina sobre a digestibilidade ruminal da FDN (drFDN). Em resumo, as dietas CT, MN e OL apresentaram valores similares (43,68; 45,71 e 45,08\%, respectivamente), enquanto a dieta $\mathrm{OM}$ apresentou menor digestibilidade ruminal da FDN que as demais (39,75\%). Segundo esses autores, embora a monensina tenha ação sobre as bactérias celulolíticas, outras espécies tolerantes ao ionóforo assumem o papel na fermentação da fibra. Possivelmente, o mesmo raciocínio seja válido para a dieta com óleo de soja. Os dados indicados neste trabalho mostraram correlação positiva entre os protozoários celulolíticos e a digestibilidade ruminal da FDN $(r=0,45)$, o que concorda com a revisão de Eugène et al.(2004). A dieta OM apresentou os menores valores de drFDN (39,75\%) e as menores contagens de protozoários $(0,08 \times 104 / \mathrm{mL})$, mostrando quase completa defaunação dos celulolíticos.

Uma das principais características da defaunação é a diminuição da concentração de $\mathrm{N}-\mathrm{NH}_{3}$ no rúmen, em decorrência da redução da atividade predatória e proteolítica dos protozoários (Doreau \& Ferlay, 1995). Entretanto, apesar de ter sido observada correlação positiva com a concentração de amônia ruminal $(r=0,47)$, a maior concentração de amônia no rúmen pode também ser decorrente da menor utilização do nitrogênio para o crescimento bacteriano, como relatado anteriormente (Eifert et al., 2005). Os demais parâmetros de fermentação ruminal, $\mathrm{pH}$ e concentração de ácidos graxos voláteis (AGV) não apresentaram relação com os ciliados.

Segundo Williams \& Coleman (1997), a proporção molar de butirato é reduzida com a defaunação. Entretanto, não foi observada relação entre as proporções de butirato e acetato e a população de ciliados ou aos celulolíticos. Contudo, o número total de protozoários mostrou correlação negativa com a proporção molar de propionato $(r=-0,50)$ e, conseqüentemente, positiva com a relação acetato propionato (relAP, $r=0,46$ ), o que sugere melhor uso energético no rúmen, devido à defaunação promovida pelos tratamentos. Por outro lado, é presumível que a defaunação afete o metabolismo do hidrogênio no rúmen (Eugène et al., 2004), onde propionato e metano são substâncias concorrentes na acepção de hidrogênio (Moss et al., 2000); portanto, aumento na proporção de propionato sugere menor perda por metano nas dietas que promoveram defaunação.

Moss et al. (2000) mostraram que existe bom relacionamento entre acetato, butirato e propionato (relação (C2 + C4)/C3) e a produção de metano. Neste trabalho, a relação $(\mathrm{C} 2+\mathrm{C} 4) / \mathrm{C} 3)$ apresentou correlação de $\mathrm{r}=0,51(\mathrm{P}=0,043)$ com o total de protozoários, sugerindo que a redução no número de protozoários imposta pelos tratamentos pode ter reduzido a geração de metano no rúmen. A monensina não diminui metano por um efeito direto sobre as arquéias metanogênicas, mas pela alteração das rotas metabólicas 
Tabela 4 - Correlação do número total de protozoários (ptz) ou o número de protozoários celulolíticos (Ptz Cel) com variáveis de consumo, digestão e fermentação ruminal

\begin{tabular}{|c|c|c|c|c|}
\hline \multirow[t]{2}{*}{ Item } & \multicolumn{2}{|c|}{ № total de protozoários } & \multicolumn{2}{|c|}{ Protozoários celulolíticos } \\
\hline & $\mathrm{r}$ & $\mathrm{P}$ & $\mathrm{r}$ & $\mathrm{P}$ \\
\hline & \multicolumn{4}{|c|}{ Consumo diário } \\
\hline CMS & 0,3890 & 0,1365 & 0,1775 & 0,5106 \\
\hline CAG & $-0,5575$ & 0,0248 & $-0,4798$ & 0,0600 \\
\hline \multirow[t]{2}{*}{ CLIN } & $-0,5613$ & 0,0237 & $-0,4787$ & 0,0607 \\
\hline & \multicolumn{4}{|c|}{ Síntese microbiana } \\
\hline $\mathrm{N}$-mic & 0,3980 & 0,1268 & $-0,0119$ & 0,9651 \\
\hline \multirow[t]{2}{*}{ EfSM } & 0,0165 & 0,9516 & $-0,1888$ & 0,4838 \\
\hline & \multicolumn{4}{|c|}{ Digestibilidade ruminal } \\
\hline drFDN & 0,1756 & 0,5154 & 0,4545 & 0,0769 \\
\hline $\mathrm{drPB}$ & $-0,2716$ & 0,3088 & $-0,2989$ & 0,2607 \\
\hline \multirow[t]{2}{*}{ drMO } & $-0,2356$ & 0,3799 & $-0,1234$ & 0,6489 \\
\hline & \multicolumn{4}{|c|}{ Parâmetro da fermentação ruminal } \\
\hline $\mathrm{pH}$ & $-0,0138$ & 0,9596 & $-0,2169$ & 0,4197 \\
\hline $\mathrm{N}-\mathrm{NH}_{3}$ & 0,3527 & 0,1803 & 0,4751 & 0,0629 \\
\hline \multirow[t]{2}{*}{ AGV } & 0,0400 & 0,8832 & 0,2370 & 0,3767 \\
\hline & \multicolumn{4}{|c|}{ Proporção molar de ácidos graxos } \\
\hline pac & 0,3296 & 0,2125 & 0,1657 & 0,5397 \\
\hline ppr & $-0,4986$ & 0,0493 & $-0,3111$ & 0,2408 \\
\hline pbut & 0,0875 & 0,7473 & 0,1408 & 0,6030 \\
\hline relAP & 0,4597 & 0,0732 & 0,2731 & 0,3061 \\
\hline
\end{tabular}

CMS, CAG, CLIN - consumos de matéria seca, ácidos graxos e ácido linoléico; N-mic e EfSM - síntese e eficiência de síntese microbiana; drFDN, drPB, drMO - digestibilidade ruminal da FDN, PB e $\mathrm{MO} ; \mathrm{pH}-\mathrm{pH}$ ruminal; $\mathrm{N}-\mathrm{NH}_{3}$ - nitrogênio amoniacal; $\mathrm{AGV}$ - ácidos graxos voláteis totais; pac, ppr, pbut - percentagens molar de acetato, propionato e butirato; relAP - relação acetato propionato.

que geram propionato no lugar de acetato, originado da maior proporção das bactérias gram-negativas, tolerantes ao ionóforo (Moss et al., 2000), como visto neste trabalho. Parte das arquéias metanogênicas vive em simbiose com protozoários e o trabalho de Guan et al. (2006) mostrou que a monensina reduziu a emissão de metano na mesma proporção com que a população de ciliados foi reduzida.

Tem-se sugerido que lipídios atuam como agentes defaunadores (Moss et al., 2000) e sua inclusão nas dietas promovem redução na produção de metano, onde a fonte de lipídio utilizada dita a magnitude do efeito promovido (Machmüller et al., 1998). Dohme et al. (2001) mostraram que lipídios inibem a produção de metano não só por redução no número de protozoários, mas também por ação direta dos lipídios sobre as arquéias metanogênicas, diferentemente do que ocorre com monensina. Embora neste trabalho não se tenha quantificado a produção de metano, mas infere-se a partir das alterações na população de protozoários e das proporções dos ácidos graxos voláteis, o trabalho de McGinn et al. (2004) mostrou que $5 \%$ de óleo de girassol foi mais efetivo que 33 ppm de monensina, ao se reduzir a produção de metano (21 e 9\%, respectivamente) quando corrigido para o mesmo nível de consumo de energia.

Esta pesquisa foi realizada a partir de um desenho experimental em quadrado latino, com pequeno intervalo de coletas, não possibilitando avaliações ao longo do tempo. Sabe-se que o efeito da monensina sobre a população de ciliados é transiente (Arakaki et al., 1997; Guan et al., 2006), o que indica que experimentos de longa duração devem ser conduzidos e avaliados em conjunto, lipídios e ionóforos, no sentido de gerar estratégias para reduzir a emissão de metano por ruminantes.

\section{Conclusões}

A utilização de monensina ou óleo de soja na dieta de ruminantes promove redução no número de protozoários, enquanto quase completa defaunação resulta quando estes dois ingredientes são fornecidos em conjunto, o que sugere que o óleo de soja e monensina apresentam efeito aditivo sobre a população de ciliados.

Os ciliados celulolíticos auxiliam na digestão ruminal da FDN e promovem, entretanto, maior acúmulo de amônia ruminal. A defaunação promove aumento das proporções de propionato nos ácidos graxos voláteis, indicando que a redução no número total de protozoários pelos tratamentos pode reduzir a emissão de metano por ruminantes.

\section{Agradecimento}

Ao Centro Nacional de Pesquisa de Gado de Leite (EMBRAPA Gado de Leite), pela cessão dos animais e dietas.

\section{Literatura Citada}

ARAKAKI, L.C.; STAHRINGER, R.C.; GARRET, J.E. et al. The effects of feeding monensin and yeast culture, alone or in combination, on the concentration and generic composition of rumen protozoa in steers fed on low-quality pasture supplemented with increasing levels of concentrate. Animal Feed Science and Technology, v.84, p.121-127, 2000.

DAYANI, O.; GHORBANI, G.R.; ALIKHANI, M. et al. Effects of dietary whole cottonseed and crude protein level on rumen protozoal population and fermentation parameters. Small Ruminant Research, v.69, p.36-45, 2007.

D’AGOSTO, M.; SANTA-ROSA, M.R. Influência do hospedeiro no perfil populacional e nas populações de ciliados do rúmen de bovinos. Revista Brasileira de Zoologia, v.15, n.2, p.389396, 1998.

D’AGOSTO, M.; CARNEIRO, M.E. Evaluation of lugol solution used for counting rumen ciliates. Revista Brasileira de Zoologia, v.16, p.725-729, 1999.

DEHORITY, B.A. Evaluation of subsampling and fixation procedures used for counting rumen protozoa. Applied and Environmental Microbiology, v.48, p.182-185, 1984. 
DOREAU, M.; FERLAY, A. Effect of dietary lipids on the ruminal metabolism in the rumen: a review. Livestock Production Science, v.43, p.97-110, 1995.

DOHME, F.; MACHMÜLLER, A.; ESTERMANN, B.L. et al. The role of the rumen ciliate protozoa for methane suppression caused by coconut oil. Letters in Applied Microbiology, v.29, p.87-92, 1999.

DOHME, F.; MACHMÜLLER, A.; WASSERFALLEN, A. et al. Ruminal methanogenesis as influenced by individual fatty acids supplemented to complete ruminant diets. Letters in Applied Microbiology, v.32, p.47- 51, 2001.

EIFERT, E.C.; LANA, R.P.; LEÃO, M.I. et al. Efeito da combinação de óleo de soja e de monensina na dieta sobre o consumo e digestão em vacas lactantes. Revista Brasileira de Zootecnia, v.34, n.1, p.297-308, 2005.

EUGÈNE, M.; ARCHIMÈDE, H.; SAUVANT, D. Quantitative metaanalysis on the effects of defaunation of the rumen on growth, intake and digestion in ruminants. Livestock Production Science, v.85, p.81-97, 2004.

FRANZOLIN, R.; DEHORITY, B.A. Efeitos do pH ruminal e ingestão alimentar na defaunação em ovinos sob rações concentradas. Revista da Sociedade Brasileira de Zootecnia, v.25, n.6, p.1207-1215, 1996.

FRANZOLIN, R.; FRANZOLIN M.H. População de protozoários ciliados e degradabilidade ruminal em búfalos e bovinos zebuínos sob dieta à base de cana-de-açúcar. Revista Brasileira de Zootecnia, v.29, p.1853-1861, 2000.

GUAN, H.; WITTENBERG, K.M.; OMINSKI, K. H. et al. Efficacy of ionophores in cattle diets for mitigation of enteric methane. Journal of Animal Science, v.84, p.1896-1906, 2006.

HRISTOV, A.N.; IVAN, M.; MCALLISTER, T.A. In vitro effects of individual fatty acids on protozoal numbers and on fermentation products in ruminal fluid from cattle fed a highconcentrate, barley-based diet. Journal of Animal Science, v.82, p.2693-2704, 2004.

IVAN, M.; MIR, P.S.; KOENIG, K.M. et al. Effects of dietary sunflower seed oil on rumen protozoa population and tissue concentration of conjugated linoleic acid in sheep. Small Ruminant Research, v.41, p.221-227, 2001.
MACHMÜLLER, A.; OSSOWSKI, D.A.; WANNER, M. et al. Potential of various fatty feeds to reduce methane release from rumen fermentation in vitro (Rusitec). Animal Feed Science and Technology, v.71, p.117-130, 1998.

McGINN, S.M.; BEAUCHEMIN, K.A.; COATES, T. et al. Methane emissions from beef cattle: Effects of monensin, sunflower oil, enzymes, yeast, and fumaric acid. Journal of Animal Science, v.82, p.3346-3356, 2004.

MOSS, A.R.; JOUANY, J.P.; NEWBOLD, J. Methane production by ruminants: its contribution to global warming. Annales de Zootechnie, v.49, p.231-253, 2000.

NATIONAL RESEARCH COUNCIL - NRC. Nutrient requirements of dairy cattle. 7.ed. Washington, D.C.: National Academy Press, 2001. 381p.

OGIMOTO, K.; IMAI, S. Atlas of rumen microbiology. Tokyo: Japan Scientific Societies Press, 1981. 231p.

ROGERS, M.; JOUANY, J.P.; THIVEND, P. et al. The effects of short-term and long-term monensin supplementation, and its subsequent withdrawal on digestion in sheep. Animal Feed Science Technology, v.65, p.113-127, 1997.

STATISTICAL ANALYSIS SYSTEM - SAS. SAS/STAT: user's guide. Version 6.12. 4.ed. v.1. Cary: SAS Institute, 1997. 890p.

SIQUEIRA, I.C.V.; D’AGOSTO, M. Comportamento e perfil de comunidade de protozoários ciliados no rúmen de bovinos. Revista Brasileira de Zoociências, v.5, n.2, p.243-252, 2003.

TOWNE, G.; NAGARAJA, T.G.; BRANDT JR., R.T. et al. Ruminal ciliated protozoa in cattle fed finishing diets with or without supplemental fat. Journal of Animal Science, v.68, p.21502155, 1990.

VALiNOTE, A.C.; NOGUEIRA FILHO, J.C.M.; LEME, P.R. et al. Fontes de lipídeos e monensina na alimentação de novilhos nelore e sua relação com a população de protozoários ciliados do rúmen. Revista Brasileira de Zootecnia, v.34, n.4, p.1418-1423, 2005.

WILliAMS, A.G.; COLEMAN, G.S. The rumen protozoa. In: HOBSON, P.N.; STEWART, C.S. (Eds.). 2.ed. The rumen microbial ecosystem. London: Blackie Academic \& Professional, 1997. p.73-139. 